\title{
COMPARATIVO DE CUSTOS E RESULTADOS EM SISTEMAS DE PRODUÇÃO DE BOVINOS: O CASO DA FAZENDA SANTA LUZIA
}

\author{
COMPARING COSTS AND RESULTS ON BOVINE CATTLE \\ PRODUCTION SYSTEMS: THE CASE OF SANTA LUZIA FARM
}

\author{
Ângela Golas ${ }^{1}$ \\ Antonielle Pagnussat ${ }^{2}$ \\ Laércio Juarez Melz ${ }^{3}$
}

\begin{abstract}
RESUMO
O preço do gado, que é determinado pelo mercado e sempre sofre variações. Muitos pecuaristas não conhecem quais são os custos de criação do rebanho, desconhecendo qual a real lucratividade na hora de vendê-lo. Com o objetivo de conhecer o custo da criação do gado de corte, foi realizada pesquisa bibliográfica, embasada em livros, teses e artigos, além de um estudo de caso, com dados levantados em uma propriedade que desenvolve apenas atividade de bovinocultura, localizada em Juína, Mato Grosso. Os resultados mostraram a importância da Contabilidade e do conhecimento dos custos pelos pecuaristas na comercialização do rebanho. Concluiu-se que a atividade de engorda de bovinos é mais lucrativa do que as atividades de cria e recria.
\end{abstract}

Palavras-Chaves: Contabilidade de Custos. Gado Bovino. Pecuária.

\begin{abstract}
The price of the cattle, that is determined by the market, and it always suffers variations. Many cattle breeders don't know which are the costs of creation of the herd, so they aren't unaware of which the profitability in the moment to sell it. Aiming to meet the cost of establishment of beef cattle, was carried out literature search, based on books, theses and articles, as well as a case study with data collected on a property that is only activity of cattle located in Juina, Mato Grosso. The results showed the importance of accounting and knowledge of farmers in marketing costs for the herd. It was concluded that the activity of fattening of cattle is more profitable than the activities of creating and recreating of cattle.
\end{abstract}

Keywords: Costs Accounting. Bovine cattle. Livestock.

\section{INTRODUÇÃO}

A atividade de bovinocultura tem grande importância para a economia brasileira. $\mathrm{O}$ Brasil é um dos maiores produtores de carne bovina e um dos principais exportadores mundiais da mesma. Estes mesmos dados se apresentam no estado do Mato Grosso, no qual a maior parte do território é ocupada pela atividade de bovinocultura (INDEA-MT, 2006).

\footnotetext{
${ }^{1}$ Contadora formada pela Universidade do Estado de Mato Grosso (UNEMAT). E-mail: angelajuina@hotmail.com

${ }^{2}$ Contadora formada pela Universidade do Estado de Mato Grosso (UNEMAT). E-mail: nelli_juina@hotmail.com

${ }^{3}$ Doutorando em Administração (UFSM), Mestre em Engenharia de Produção (UFSCar), Professor de contabilidade da Universidade do Estado de Mato Grosso (UNEMAT). E-mail: laercio@ unemat.br 
A contabilidade é a grande aliada dos pecuaristas, pois permite que os produtores conheçam os custos e o lucro da produção. É importante também para produtores que desenvolvem mais de uma atividade (cria, recria, engorda ou a combinação destas) ou que pretendem migrar de uma atividade para outra.

A Contabilidade de Custos é a ferramenta que permite conhecer e alocar, de forma mais próxima do real, os custos diretos e indiretos da produção. A Contabilidade Rural, por sua vez, cuida das particularidades das atividades rurais, que diferem das atividades comerciais. Agrupando o conhecimento das duas áreas é possível que a gestão da propriedade melhore.

Um dos fatores que influenciam no preço do rebanho é a lei da demanda e da oferta. Quanto maior a demanda, maior o preço, quanto maior a oferta, menor será o preço pago pelo mercado.

O preço do gado é determinado pelo mercado. Isso torna mais importante o conhecimento dos custos da criação dos bovinos, para a tomada de decisão na hora da venda, saber qual o momento certo de realizá-la. Quando o preço está em baixa é necessário saber optar por fazer corte de gastos, vender para não acumular mais gastos ainda ou segurar o plantel para pressionar o aumento do preço.

Foi realizado um estudo de caso, no município de Juína - MT, com o intuito de conhecer qual a atividade é mais lucrativa para o proprietário, a atividade de cria e recria ou a atividade de engorda. Uma vez que este pecuarista está iniciando na atividade de engorda de animais.

O objetivo geral deste artigo foi fazer o levantamento dos custos da atividade de bovinocultura no sistema de cria-recria e engorda na propriedade Santa Luzia, localizada em Juína - MT. Especificamente pretendeu-se levantar e comparar dos custos para a atividade de bovinocultura de corte, levantar dos preços praticados no mercado para o gado de corte e identificar qual a atividade entre as desenvolvidas é mais vantajosa para este proprietário.

O problema da pesquisa: Qual das atividades bovinas praticadas proporciona melhores resultados ao proprietário da propriedade Santa Luzia: cria-recria ou engorda?

\section{REVISÃO TEÓRICA}

A revisão teórica foi estruturada para melhor compreensão dos assuntos abordados neste estudo. Nas seções seguintes são revisados alguns conceitos importantes sobre 
Comparativo de custos e resultados em sistemas de produção de bovinos: o caso da fazenda Santa Luzia Ângela Golas

Antonielle Pagnussat

Laércio Juarez Melz

Contabilidade Rural, Contabilidade de Custos, atividade rural e custos de produção de bovinos.

\title{
2.1 Contabilidade Rural
}

Marion (2006, p. 25), conceitua Contabilidade Rural como uma ramificação da Contabilidade Geral. Contabilidade Rural é a Contabilidade Geral aplicada às empresas do meio rural. Empresas rurais podem exercer atividades agrícolas, zootécnicas, pecuárias, agropecuárias e agroindustriais.

Para Marion (2004, p. 26), Contabilidade é:

\begin{abstract}
o instrumento que fornece o máximo de informações úteis para a tomada de decisões dentro e fora da empresa. [...] Todas as movimentações possíveis de mensuração monetária são registradas pela contabilidade, que, em seguida, resume os dados registrados em forma de relatórios e os entrega aos interessados em reconhecer a situação da empresa. Esses interessados, através de relatórios contábeis, recordam os fatos acontecidos, analisam os resultados obtidos, as causas que levaram àqueles resultados e tomam decisões em relação ao futuro.
\end{abstract}

Para Crepaldi (2006, p. 22), a Contabilidade é fundamental para a vida econômica das empresas, tanto das grandes como das pequenas empresas, uma vez que a contabilidade coleta, apresenta e interpreta os fatos econômicos.

Empresas Rurais são "aquelas que exploram a capacidade produtiva do solo por meio do cultivo da terra, da criação de animais e da transformação de determinados produtos agrícolas" (MARION, 2006, p. 24).

Entre as atividades rurais se destacam a atividade agrícola, que desenvolve produção de vegetais; a atividade zootécnica, que desenvolve a criação de animais; e a atividade agroindustrial, que são as indústrias processadoras de produtos rurais. Indústrias rurais tratam do beneficiamento e transformação de produtos agrícolas e zootécnicos.

O presente artigo selecionou a atividade zootécnica como objeto de estudo. Especificamente atividade pecuária (criação de bovinos), uma vez que o Brasil é o detentor de um dos maiores rebanhos de bovinos atualmente.

\subsection{Ano agrícola na atividade rural}

Ao final de cada exercício social ou período contábil, as empresas devem apresentar as demonstrações contábeis ou financeiras. Exercício social compreende normalmente um 
período de 12 meses, no qual se dá o encerramento para apuração de resultados. Nas empresas comerciais, geralmente, o exercício social coincide com o ano civil, iniciando em 01 de janeiro e encerrando em 31 de dezembro de cada ano (MARION, 2004, p. 45).

Conforme Marion (2006, p. 26), na atividade rural o término do ano civil não é o melhor período para o encerramento do exercício social, como nas empresas comerciais. As empresas comerciais têm receitas e despesas constantes, o mesmo não ocorre na atividade rural, então, a empresa rural deve adotar o período de apuração dos resultados de acordo com cada atividade.

$\mathrm{Na}$ atividade pecuária o melhor período para o encerramento do exercício social é após o nascimento ou o desmame dos bezerros. Para as empresas que planejam o nascimento dos bezerros em certo período do ano é mais fácil determinar a data do encerramento, já para as empresas que não determinam este período é mais complicado, então estas devem escolher o período com a maior concentração de nascimentos (MARION, 2006, p. 28).

Há ainda empresas que encerram o exercício social após a venda de animais para os frigoríficos, é o caso das empresas que desenvolvem a atividade de engorda. Neste caso, há receitas para serem confrontadas com as despesas. Enfim, o melhor momento para o encerramento do exercício social deve ser determinado de acordo com cada atividade.

A atividade agropecuária é desenvolvida tanto por pessoas físicas como por pessoas jurídicas. Considerando que pessoa física é todo ser humano, sem exceções, cuja existência termina apenas com a morte. Pessoa jurídica é a união de indivíduos que formam uma nova pessoa, com personalidade própria, distinta de seus membros, com capacidade de exercer direitos e assumir responsabilidades (MARION, 2006, p. 29).

No Brasil, a atividade rural é mais habitual às pessoas físicas, em razão das vantagens legais. Os pequenos e médios produtores rurais, caracterizados como pessoas físicas, estão desobrigados de manter a escrituração contábil regular, precisam manter apenas o Livro Caixa, com escrituração simplificada (SRF, 1996).

Conforme Instrução Normativa 17/96, Artigo 22, § $3^{\circ}$, da Secretaria da Receita Federal do Brasil: " $§ 3^{\circ}$ Quando a receita bruta total auferida no ano-calendário não exceder a $\mathrm{R} \$ 56.000,00$ (cinqüenta e seis mil reais) é facultada a apuração mediante prova documental, dispensada a escrituração do livro Caixa".

Este parágrafo regulamenta quanto a não obrigação da escrituração contábil das pessoas físicas consideradas produtores de pequeno e médio porte com receita inferior ou igual a $\mathrm{R} \$ 56.000,00$, desta forma, é opcional a escrituração do Livro Caixa. 


\subsection{Classificação da atividade pecuária}

Atividade Pecuária é a "arte de criar e tratar gado". (FREIRE, p. 154, citado por MARION, 2007, p. 20). São considerados como gado os animais de campo, criados para serviços rurais, consumo, fins industriais e comerciais. Animais bovinos, bubalinos, caprinos, eqüinos, ovinos e outros, classificam-se como gado.

A atividade pecuária de bovinos de corte é dividida em cria, recria e engorda. De acordo com Marion (2006, p. 106), pode ser combinada da seguinte forma: cria, recria, criarecria, cria-recria-engorda, recria-engorda ou engorda. Marion (2006, p. 106), ainda define cada uma das atividades:

a) Cria: a atividade básica é a produção de bezerros que só serão vendidos após o desmame. Normalmente, a matriz (de boa fertilidade) produz um bezerro por ano.

b) Recria: a atividade básica é, a partir do bezerro adquirido, a produção e a venda do novilho magro para a engorda.

c) Engorda: a atividade básica é, a partir do novilho magro adquirido, a produção e a venda de novilho gordo.

Para Marion (1996, p. 49), a atividade de cria consiste na etapa da atividade de criação dos bezerros, do nascimento até o desmame (período igual ou inferior a 12 meses). A atividade de recria é o período a partir do desmame do bezerro até o período denominado como novilho magro para engorda (entre 13 a 23 meses). Engorda é a atividade a partir do novilho magro para engorda até a venda para o abate.

\subsection{Contabilidade de Custos}

Contabilidade de Custos é o ramo da Contabilidade que fornece informações quantitativas da rentabilidade operacional, oferecendo dados para o planejamento e a tomada de decisões. "O objetivo principal da Contabilidade de Custos é produzir informações que atendem as necessidades da administração: determinação da rentabilidade, controle das operações, planejamento e tomada de decisões." (LEONI; LEONI, 2004, p. 80).

A Contabilidade de Custos é uma importante ferramenta na economia, em razão da competitividade do mercado. As empresas precisam conhecer seus custos para poder planejálos e controlá-los, quando possível, para manter preços competitivos no mercado. Conforme afirma Van Derbeck e Nagy (2003, p. 13): 
A contabilidade de custos fornece os dados detalhados sobre custos que a gestão precisa para controlar as operações atuais e planejar para o futuro. [...] a contabilidade de custos fornece as informações que permitem à gerência alocar recursos para as áreas mais eficientes e rentáveis da operação.

A contabilidade de custos teve sua origem a partir da contabilidade financeira, para suprir as necessidades dos seus usuários, principalmente das empresas industriais, que tinham necessidades de conhecer o custo dos produtos fabricados. Anteriormente, o valor dos estoques era composto apenas pelo valor das compras, não eram ativados os valores gastos para a obtenção dos produtos finais (MARTINS, 2003).

Kanitz, citado por Iudícibus (1998, p. 114) afirma que, "a contabilidade financeira preocupa-se com o regime de competência de receitas e despesas, a de custo, sem ferir o regime de competência, preocupa-se com o custeio da produção.”.

Com o desenvolvimento potencial da contabilidade de custos, outros ramos de atividades passaram a utilizar suas ferramentas de controle, tais como, empresas financeiras, comerciais e prestadoras de serviços.

\subsection{Classificação de Custos}

Para ser realizada a análise e apuração dos custos, conforme Batalha (2007, p. 458) devem estar claro os seguintes itens:

o objeto e o propósito do custeio a ser elaborado. Isto porque todas as etapas posteriores dependerão dos propósitos preestabelecidos. Após a identificação do objeto de custeio, deve ser realizada a separação entre custos diretos e indiretos.

Custos diretos são aqueles que podem ser apropriados ao produto de forma direta, são aplicados diretamente ao produto ou serviço e podem ser identificados no produto final pela relevância de valores destes custos (BATALHA, 2007, p. 434).

Para Megliorini (2002, p. 11), custos diretos são os custos que podem ser alocados ao produto conforme o consumo, podendo ser mensurados. Matéria-prima e mão-de-obra são os exemplos mais claros de custos diretos.

Ainda para Batalha (2007, p. 433), custos indiretos são aqueles que são estimados através de bases de rateio, em virtude da impossibilidade de medição de forma direta da utilização de determinados recursos na produção de bens ou serviços. Estes custos são 
Comparativo de custos e resultados em sistemas de produção de bovinos: o caso da fazenda Santa Luzia Ângela Golas

Antonielle Pagnussat

Laércio Juarez Melz

indispensáveis para a produção, porém, não são custos relevantes para serem alocados de forma direta ao produto final.

Megliorini (2002, p. 11), considera custos indiretos são aqueles que não são mensurados a cada produto. Os custos indiretos são rateados e alocados aos produtos. O critério de rateio utilizado pode ser definido baseado na hora da mão-de-obra, hora das máquinas utilizadas na fabricação dos produtos ou de acordo com o volume de matéria-prima consumida.

Além da classificação em diretos e indiretos, os custos também são classificados em variáveis e fixos. Para Marion (1996, p. 61), custos variáveis são aqueles que variam proporcionalmente ao volume de produção. Estes custos são ligados com o funcionamento da empresa e dependem do grau de utilização dos fatores de produção, principais exemplos são a mão-de-obra direta e os insumos (matéria-prima).

"Custos variáveis são aqueles relacionados diretamente com o volume de produção. [...] Os custos fixos são aqueles que independem das variações ocorridas no volume de produção daquele período.” (Batalha, 2007 p. 434).

Conforme a figura 1 , os custos variáveis variam no total da produção e permanecem constantes no produto unitário.
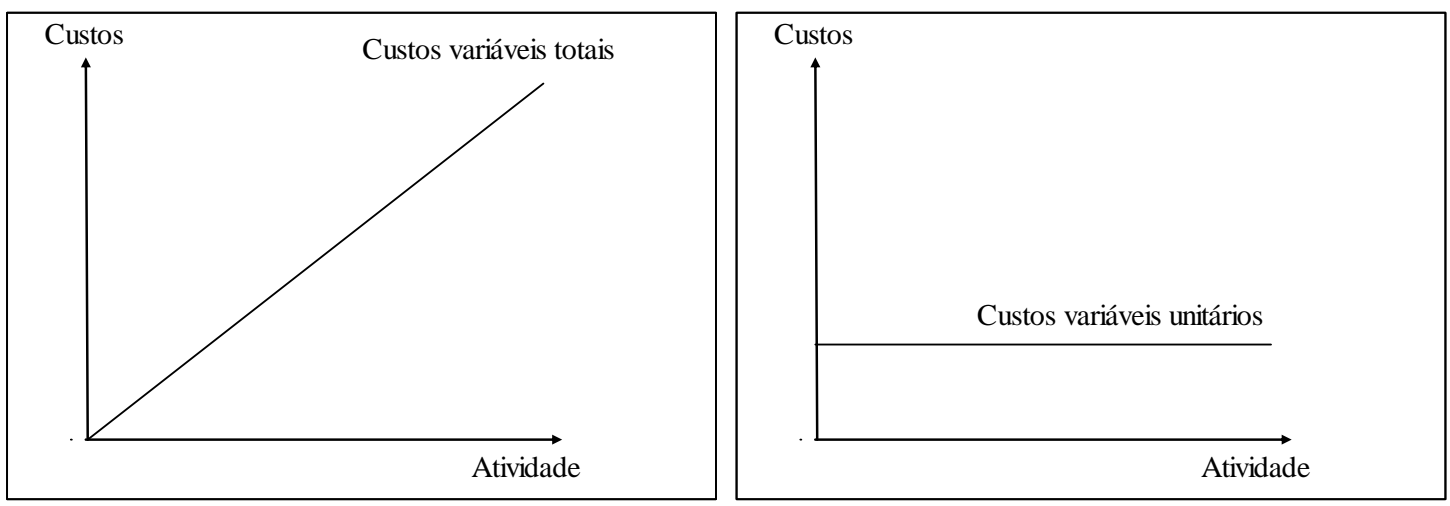

Figura 1. Análise dos custos variáveis totais e unitários. Fonte: Batalha, 2007, p. 434

Já os custos fixos são aqueles que ocorrem independente da produção, não alteram os valores caso não haja produção ou a produção sofra alterações radicais de um período para outro. Marion (1996, p. 61), considera os custos fixos como custos oriundos da posse de ativos. Exemplo: depreciação, aluguéis e seguros. 
Comparativo de custos e resultados em sistemas de produção de bovinos: o caso da fazenda Santa Luzia Ângela Golas

Antonielle Pagnussat

Laércio Juarez Melz

Os custos fixos não variam dentro de um intervalo de produção, mas podem diminuir conforme o aumento da produção, conforme a figura 2.
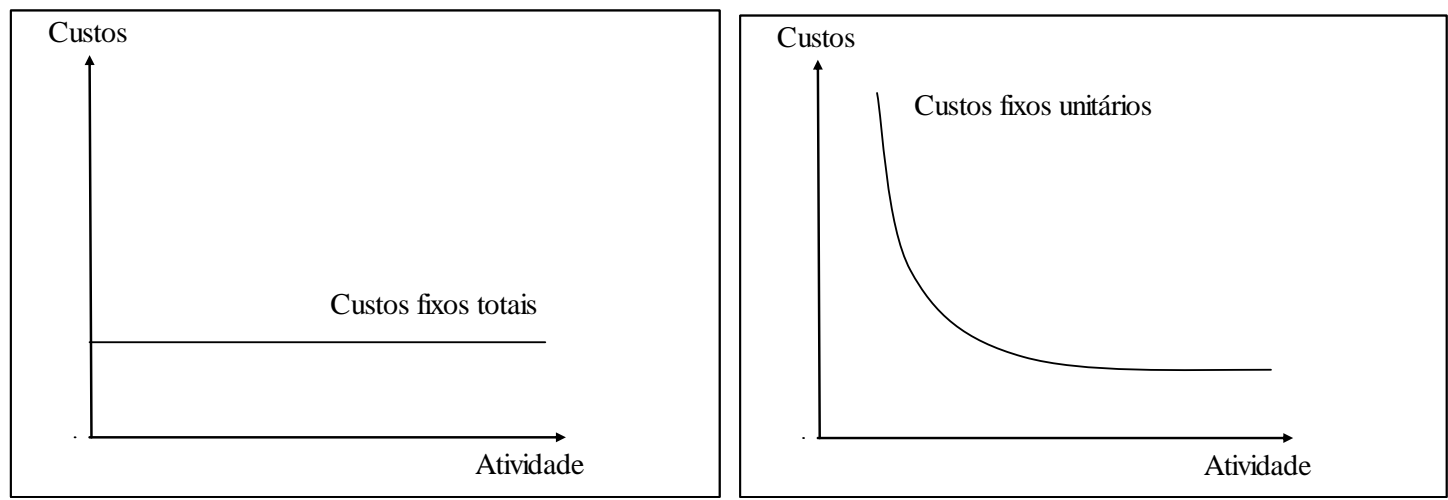

Figura 2. Análise dos custos fixos totais e unitários. Fonte: Batalha, 2007, p. 435

\subsection{Métodos de custeio}

O conhecimento dos custos de produção em uma empresa é essencial para a tomada de decisões. É vital para uma entidade saber quais são os custos dos produtos para a formação de preços, conhecimento da margem de contribuição e decidir o mix de produtos ofertados aos clientes.

A partir de suas principais funções, controle e decisão, foram desenvolvidos métodos de custeio para atender aos objetivos. Custeios são métodos de apropriação dos custos aos produtos fins.

Este artigo tem como foco os custos de produção da bovinocultura, sobre este assunto, apresenta-se nas seções seguintes o Método de Custeio por Absorção. O Método de Custeio Baseado em Atividades (ABC) e Método do Valor de Mercado também são apresentados para melhor compreensão do trabalho.

\subsubsection{Método de custeio por absorção}

O método de custeio por absorção ou custeio completo aloca os custos diretos e indiretos aos produtos. Assim, os produtos absorvem todos os custos incorridos no período em função da produção dos mesmos. Já as despesas são lançadas diretamente na apuração do resultado do exercício. 
Contabilmente, gastos, custos, despesas e investimentos têm conceitos diferentes. Padoveze (2004, p. 311), conceitua gastos, custos, despesas e investimentos da seguinte forma:

\begin{abstract}
Gastos são todas as ocorrências de pagamentos ou recebimentos de ativos, custos ou despesas. Significa receber serviços e produtos para todo o processo operacional, bem como os pagamentos efetuados e recebimentos de ativos. Como se pode verificar, gastos são ocorrências de grande abrangência e generalização.

Custos são os gastos necessários para fabricar os produtos da empresa. São os gastos efetuados pela empresa que farão nascer os seus produtos. Portanto, podemos dizer que os custos são os gastos relacionados aos produtos, [...]. De modo geral são os gastos ligados à área industrial da empresa.
\end{abstract}

Despesas são os gastos necessários para vender e enviar os produtos. De modo geral, são os gastos ligados às áreas administrativas e comerciais. O custo dos produtos, quando vendidos, transformam-se em despesas.

Investimentos são os gastos efetuados em ativos ou despesas e custos que serão imobilizados ou diferidos. São gastos ativados em função de sua vida útil ou benefícios futuros.

Martins (2003, p. 24), define de forma mais clara e simplificada gastos, custos e despesas. Gastos é a compra de produtos ou serviços que gera desembolso. Gastos podem ser de compras de matérias-primas, com mão-de-obra, compra de imobilizado, etc. O gasto é realmente efetivado quando a propriedade passa a ser da empresa, gerando desembolso ou assunção da dívida.

Ainda para Martins (2003, p. 25), custos são os gastos relativos a bens e serviços utilizados na produção de outros. E despesas são bens e serviços consumidos de forma direta ou indireta para a obtenção de receitas.

Pode-se considerar que no método de custeio por absorção, os custos diretos são de fácil alocação, como o propósito é o custo de fabricação dos produtos ou serviços. Os custos indiretos não podem ser alocados diretamente aos produtos, devem ser apropriados através de critérios de rateios, de forma proporcional entre custos indiretos, o mais próximo ao real.

Batalha (2007, p. 460), evidencia que "a melhor forma de rateio é a que melhor expressa a relação de proporcionalidade entre o parâmetro de distribuição e o volume de custos indiretos". Para que isso ocorra é necessário que o processo de produção seja muito bem conhecido. Outra forma de distribuir os custos indiretos é através de centros de custos, que posteriormente serão alocados aos produtos (figura 3). $\mathrm{O}$ mesmo acontece com os Centros de Apoio, que recebem os custos indiretos e depois são alocados aos produtos. 


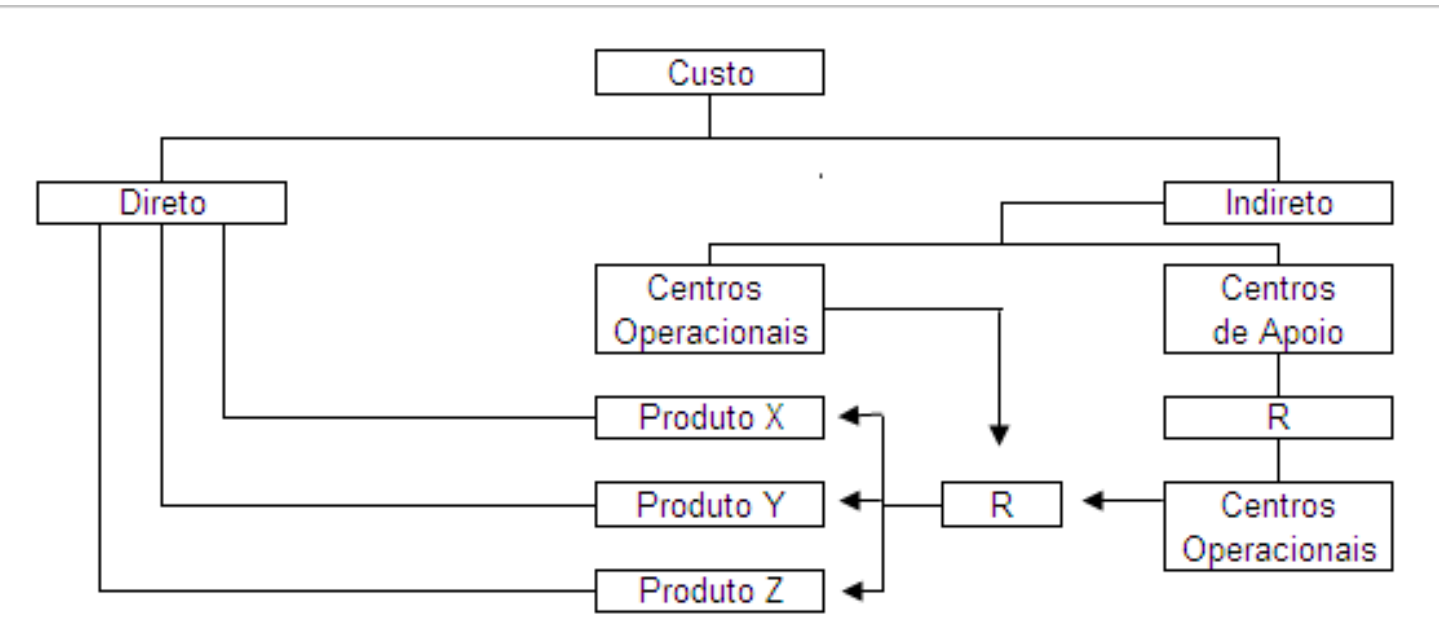

Figura 3 - Esquema geral do sistema de custeio por absorção. Fonte: Batalha (2007, p. 459), adaptada de Martins (2004).

Crepaldi (2006, p. 139), apresenta algumas vantagens e desvantagens da aplicação do método de custeio por Absorção, que são por ele denominados pontos positivos e críticas, conforme o quadro 1 :

\section{Pontos Positivos}

Fixação de preços de vendas mais reais, pois engloba todos os custos da empresa nos custos unitários dos produtos.

Baseia-se nos Princípios Fundamentais de Contabilidade.

Demonstra índices de liquidez mais reais.

No Brasil, aceito pelo Fisco.

\section{Críticas}

Os custos dos produtos não poderão ser comparados em bases unitárias quando houver alteração no volume de produção.

A forma de atribuição de custos indiretos é feita por meio de rateios, o que complica e aumenta o trabalho administrativo, além de conferir um grau de subjetividade a essa atribuição.

Não oferece informações suficientes para a tomada de decisões, já que muitas das decisões se baseiam em análise separada dos custos fixos e variáveis: não permite análise do tipo relação Custo/Volume/Lucro.

Dificulta o controle orçamentário e a determinação de padrões.

Quadro 1: Pontos positivos e críticas ao Método de Custeio por Absorção.

O método de custeio por absorção é o método de custeio aceito pela Legislação Brasileira, por aplicar os princípios contábeis e por apropriar apenas os custos de produção aos produtos. Martins (2003, p. 38), "Não é um princípio contábil propriamente dito, mas uma metodologia decorrente deles, nascida com a própria Contabilidade de Custos.” E, ainda, "no Brasil é utilizado obrigatoriamente, com pequenas exceções”. 


\subsubsection{Método de Custeio Baseado em Atividades (ABC)}

Método de Custeio Baseado em Atividades (ABC), conforme Martins (2003, p. 87), “é uma metodologia de custeio que procura reduzir sensivelmente as distorções provocadas pelo rateio arbitrário dos custos indiretos".

O diferencial do Método $\mathrm{ABC}$ é a identificação e separação das atividades para que desta forma seja feito o rateio dos custos indiretos. Para isso, é necessário identificar quais são as atividades mais importantes e alocar os custos indiretos de forma mais coerente possível.

Alguns custos indiretos devem ser rateados de acordo com a utilização em cada atividade, por exemplo, a mão-de-obra indireta, que muitas vezes é utilizada em vários departamentos pode ser rateada proporcionalmente ao volume de produção de cada atividade.

No método de custeio baseado em atividades, a alocação dos custos acontece da seguinte forma: alocação de custos diretos, rastreamento e rateio dos custos indiretos.

\footnotetext{
A alocação direta se faz quando existe uma identificação clara, direta e objetiva de certos itens de custos com certas atividades. Pode ocorrer com salários, depreciações, viagens material de consumo, etc.

O rastreamento é uma alocação com base na identificação da relação de causa e efeito entre a ocorrência da atividade e a geração dos custos. Essa relação é expressa através de direcionadores de custos de primeiro estágio, também conhecidos como direcionadores de custos de recursos. (MARTINS, 2003, p. 94)
}

Os direcionadores de custos de recursos são fatores que influenciam na quantidade de trabalho, também são utilizados no processo de apuração para calcular o consumo de produtos em cada atividade. Principais exemplos de direcionadores são: número de empregados, área ocupada, hora-homem ou hora-máquina.

$\mathrm{O}$ rateio no custeio $\mathrm{ABC}$ é utilizado apenas quando não há meios de alocar os custos indiretos de forma direta ou através do rastreamento. Uma vez que, o objetivo do ABC é custear produtos através de um sistema tradicional de custos, com departamentos e separação de centros de custos, para que possam ser identificadas as principais atividades e a elas atribuídos os custos.

\subsubsection{Método de Valor de Mercado}

Valor de mercado é o valor pelo qual alguma coisa pode ser vendida, em razão da oferta e da procura do produto, em determinado local e época. (SÁ, 2006, p. 208). Aplicado 
Comparativo de custos e resultados em sistemas de produção de bovinos: o caso da fazenda Santa Luzia Ângela Golas

Antonielle Pagnussat

Laércio Juarez Melz

diretamente a Contabilidade Rural ou Contabilidade Pecuária, o Método de Valor de Mercado é o custo do plantel avaliado considerando o valor do preço de mercado, geralmente maior que o custo de criação dos animais, sendo contabilizado no estoque pelo valor de mercado do gado, atualizado a cada ano (MARION, 2006).

A diferença entre os valores de mercado e de custo dos bovinos é o ganho ou perda econômica. No ganho econômico não há movimentação monetária e, sim valorização do plantel, (Superveniências Ativas). Em caso de perda econômica, há desvalorização do rebanho (Insubsistências Ativas).

Marion (2006, p.115), Superveniências Ativas são "acréscimos, ganhos em relação ao Ativo da empresa. São os acréscimos que ocorrem em virtude de nascimento de animais e ganhos que ocorrem do crescimento natural do gado. São as variações patrimoniais positivas”.

E insubsistências ativas são "reduções do ativo da empresa causadas por perdas, fatos anormais, fortuitos e imprevistos. É o caso típico de mortes, desaparecimentos de animais do rebanho etc. São as variações patrimoniais negativas, ou seja, as diminuições reais do ativo." As insubsistências ativas devem ser deduzidas das superveniências ativas para a apuração do resultado.

\subsection{Custo de oportunidade}

Custo de oportunidade representa a perda de um benefício pela não-aplicação de recursos na melhor oportunidade. O tempo é um bom exemplo de custo de oportunidade, quando se deixa de trabalhar para estudar, sacrificando a receita que se poderia obter durante esse período, esse é o custo da educação (O’SULLIVAN E SHEFFRIN, 1998, p. 16).

Vasconcellos e Garcia (2004, p. 221), definem como custo de oportunidade "o grau de sacrifício que se faz ao optar pela produção de um bem, em termos da produção alternativa sacrificada". Já para O'Sullivan e Sheffrin (1998, p. 16) "custo de oportunidade de alguma coisa é aquilo que você sacrifica para obtê-la." Os custos de oportunidade podem ser explícitos ou implícitos. Pode ocorrer ou não o desembolso monetário.

Os custos de oportunidade são implícitos, portanto não são contabilizados, uma vez que não houve saída ou entrada de caixa, são apenas estimativas do valor que a empresa poderia ter ganhado se algumas oportunidades tivessem sido melhor aproveitadas. Vasconcellos e Garcia (2004, p. 71), exemplificam algumas destas oportunidades: o valor que poderia ser ganho com a aplicação de dinheiro parado no caixa, aluguel de prédio desocupado 
Comparativo de custos e resultados em sistemas de produção de bovinos: o caso da fazenda Santa Luzia Ângela Golas

Antonielle Pagnussat

Laércio Juarez Melz

ou o salário potencial de empregados em outra atividade. Os custos de oportunidade explícitos são os gastos com desembolso de dinheiro, como pagamento de aluguel.

O custo de oportunidade nem sempre pode ser conhecido no momento em que ocorre, não são como os custos de caixa, que são concretos. Custo de caixa são as saídas de caixa. Por não ser um custo realizado, o custo de oportunidade, nem sempre é considerado para a tomada de decisões.

\subsection{Depreciação}

Depreciação é o desgaste dos bens do Ativo Imobilizado em razão do seu uso, possíveis acidentes e da obsolescência. No processo de depreciação o valor original do bem é reduzido de acordo com a tabela do Imposto de Renda. O Imposto de Renda determina por meio de uma tabela qual o tempo de vida útil de cada bem imobilizado e suas taxas de depreciação (MARION, 2004).

Marion (2004, p. 212):

Então, a taxa de Depreciação Anual, é estabelecida em função do prazo de vida útil do bem a depreciar. Assim, se um bem pode ter duração de cinco anos, admite-se uma taxa anual de $20 \%$, isso porque a taxa anual corresponde à divisão de $100 \%$ pelo número de anos do prazo de vida útil do bem.

No custo do Ativo Imobilizado, de modo geral, não é considerada apenas depreciação, também pode existir amortização ou exaustão. Depreciação é o processo contábil para a conversão do ativo imobilizado em despesas do período pela utilização dos mesmos. Amortização é a perda do valor de capital aplicado ao Ativo Intangível. Exaustão é a perda de valor dos recursos minerais ou florestais, assim como os equipamentos utilizados, em função da exploração (MARION, 2004).

Existem algumas divergências de conceituação entre os autores, Ramos apud Marion (2006, p. 65), por sua vez, conceitua da seguinte forma:

amortização, em sentido amplo, seria aplicada a quaisquer tipos de bens do ativo fixo, com vida útil limitada. Depreciação seria o sinônimo de amortização, em sentido amplo, porém sendo aplicada somente aos bens tangíveis, como máquinas, equipamentos, móveis, utensílios, edifícios, etc. Exaustão seria sinônimo de amortização em sentido amplo, porem sendo aplicada somente aos recursos naturais exauríveis, como reservas florestais, petrolíferas, etc. Amortização, em sentido restrito, se confundiria com o seu sentido amplo, mas somente quando aplicada aos bens intangíveis de duração limitada, como as patentes, as benfeitorias em propriedades de terceiros etc. 
$\mathrm{Na}$ agropecuária, a depreciação é aplicada em casos de cultura permanente de empreendimentos próprios, da qual serão extraídos frutos. Na linha da pecuária são depreciados os implementos agrícolas, que são equipamentos e maquinários.

Marion (2006, pg. 70) diz que o gado reprodutor, animais de trabalho e outros animais que estejam no Ativo Permanente também são depreciados, por considerar que estes animais perdem capacidade produtiva com o passar dos anos. No caso destes animais, a depreciação passa a ser aplicada a partir do momento que atingirem a fase adulta. Enquanto estiveram em fase de crescimento, não são depreciados por ainda não terem atingido a vida útil e ainda estarem acumulando valores.

Os animais reprodutores, na vida adulta atingem uma fase de máxima eficiência e depois entram numa fase de declínio. O correto seria constatar o início fase de perda de produtividade para começar a depreciação, porém, é muito difícil detectar essa fase. Então, o processo de depreciação começa a partir do momento em que o animal passa para a condição de reprodutor (MARION, 2006).

As pastagens, tanto as naturais como as artificiais, são exauridas. Pastagens naturais são áreas que não precisam ser cultivadas, onde não há necessidades de plantar o capim para o sustento do gado, já com as pastagens artificiais acontece o contrário, há necessidade de plantio e manejo constate do capim (MARION, 2006).

A pastagem é considerada uma cultura permanente, se esgota com tempo ou precisa de constante manejo e não produz frutos, devem sofrer exaustão com base no tempo de vida útil, que pode ser determinado através de estudos específicos da área.

Para Marion (2006, pg. 76), a amortização é aplicada nos caso de gastos com melhorias no solo que proporcionem o aumento da capacidade produtiva, implantação de novas propriedades ou gastos com pesquisas científicas para melhorar a genética do plantel.

O prazo mínimo estabelecido para a amortização pelo Imposto de Renda é de 5 (cinco) anos e a Lei das Sociedades por Ações, estabelece o máximo de 10 (dez) anos. De acordo com estes prazos as empresas podem optar por um percentual de $10 \%$ a $20 \%$ ao ano para transformar estes ativos em custos (MARION, 2006).

\section{ATIVIDADE DE BOVINOCULTURA}


Conforme levantamento da EMBRAPA (2005), o Brasil atualmente é o segundo maior produtor de bovinos do mundo (cerca de 190 milhões de cabeças), ficando atrás apenas da Índia, onde a produção de carne é menor em função dos aspectos culturais que interferem no consumo de carne bovina. No Brasil "a bovinocultura de corte se desenvolve em todo território nacional, apesar de todas as diferenças regionais implicando em diferentes estágios de desenvolvimento desta atividade" (EMBRAPA, 2005).

Tratando-se de pastagens, de acordo com a EMBRAPA, o Brasil possui uma área ao redor de 225 milhões de hectares de pastagens, produzindo mais de 7 milhões de toneladas de carne bovina ao ano. Além de abastecer o mercado interno, o Brasil também se destaca no mercado mundial, tendo alcançado a condição de maior exportador de carne bovina em 2003, com mais de 1,3 milhão de toneladas de carne, no valor de US\$ 1,5 bilhão.

\title{
3.1 Criação de gado intensivo e extensivo
}

O sistema de criação de gado está dividido ser extensivo, semi-intensivo e intensivo. A pecuária de corte brasileira é caracterizada pela exploração do sistema extensivo, porém, há crescente adoção de sistemas pastoris intensivos, de semi-confinamento e de confinamento (AGUIAR e BARIONI, 2004).

No sistema extensivo de criação de gado de corte, os animais vivem soltos na natureza, para isso é utilizada uma grande extensão de terra. O manejo é feito apenas com o fornecimento de alguns tipos de complementos alimentares em pontos específicos da propriedade para atrair os animais (GREIF, 2008).

O custo desse sistema é baixo e exige número de pessoal reduzido para cuidar dos animais, duas pessoas são o bastante para cuidar 1.000 cabeças de animais. Neste sistema, o animal deve ser manejado periodicamente de uma pastagem para outra (GREIF, 2008).

De acordo com Aguiar e Barioni (2004):

\begin{abstract}
A pecuária extensiva consolidou-se no Brasil devido à grande disponibilidade de terra e a alta volatilidade financeira que estimulou o investimento em terra e gado como reserva de capital, particularmente nas décadas de 70 e 80. Entretanto, a conjuntura atual é marcada pela estabilidade econômica, expansão de outras atividades agrícolas (inclusive relacionadas ao crescimento da demanda mundial por energia), restrições cada vez maiores à expansão das áreas de pastagens e preocupação crescente com o impacto ambiental da pecuária de corte.
\end{abstract}

O sistema semi-intensivo depende da "implantação de forrageiras, as quais sofrem um pastoreio racional, através de algumas subdivisões de pastagens, o que leva a uma maior 
capacidade de suporte por unidade de área." (MARION, 2007, p. 20). No sistema semiintensivo há o controle de vacinas, vermífugos e minerais. As pastagens também são corrigidas constantemente, assim como o solo (MARION, 2007, p. 20).

Sistema intensivo, também denominado de confinamento, de criação de bovinos de corte tem sido cada vez mais adotado pelos pecuaristas brasileiros porque permite aumentar a produção de carne no período de entressafra, período em que o preço do boi é maior (GRAEF, 2008). As vantagens da adoção desse sistema é a redução da área ocupada, com maior produtividade por área, ganho de peso por animal maior em um espaço de tempo menor e maior rentabilidade.

Confinamento é o sistema de criação de bovinos em que lotes de animais são encerrados em piquetes ou currais com área restrita, e onde os alimentos e água necessários são fornecidos em cochos. É mais propriamente utilizado para a terminação de bovinos, que é a fase da produção que imediatamente antecede o abate do animal, ou seja, envolve o acabamento da carcaça que será comercializada (CARDOSO, 2000)

O investimento inicial para a implantação do sistema de confinamento é mais elevado do que na criação extensiva, mas as vantagens econômicas geradas possibilitam um retorno rápido do capital aplicado. Isso porque o confinamento pode ser usado até mesmo em pequenas propriedades, racionalizando o uso da terra e evitando desmatamentos ou exploração inadequada do solo (QUADROS, 2009).

Em geral, o gado comercial só vai para o confinamento no período da seca, período em que há escassez de pastagens. Porém, estes animais podem ser confinados durante todo o ano. Enquanto no sistema extensivo é necessário dispor de 1 a 2 hectares (10.000 metros quadrados a 20.000 metros quadrados) de pastagens por animal por ano, no confinamento só há necessidade de 10 metros quadrados por cabeça (QUADROS 2009).

\subsection{Bovinocultura no estado do Mato Grosso}

O rebanho de bovinos mato-grossense é, atualmente, o maior do país. Em 2006, o rebanho Mato-grossense era de 26.172.578 cabeças, conforme levantamento realizado pelo Instituto de Defesa Agropecuária do Mato Grosso (INDEA/MT), cerca de 12\% do rebanho nacional, estando a maior parte do rebanho concentrado no norte e no sudeste do estado. As terras do estado são concentradas em grandes propriedades, com mais de 1.000 ha. (um mil 
Comparativo de custos e resultados em sistemas de produção de bovinos: o caso da fazenda Santa Luzia Ângela Golas

Antonielle Pagnussat

Laércio Juarez Melz

hectares), que representam 10,2\% dos estabelecimentos agropecuários e ocupam $82,2 \%$ do território do estado (MEISTER, 2007).

O processo de colonização do município de Juína se deu por intermédio da CODEMAT (Companhia de Desenvolvimento de Mato Grosso), a partir do ano de 1978, através da venda de glebas pelo Governo do Estado, conforme projetos de colonização de terras públicas (MEISTER, 2007).

No município de Juína, o rebanho bovino para corte, de acordo com os dados do último levantamento do IBGE em 2006, é de 533.595 cabeças, distribuídos numa área de 661.559 he., com 1.992 propriedades. A evolução do tamanho do rebanho mato-grossense de gado bovino, em relação ao Brasil, tem aumentado pouco desde 2000 (figura 4).

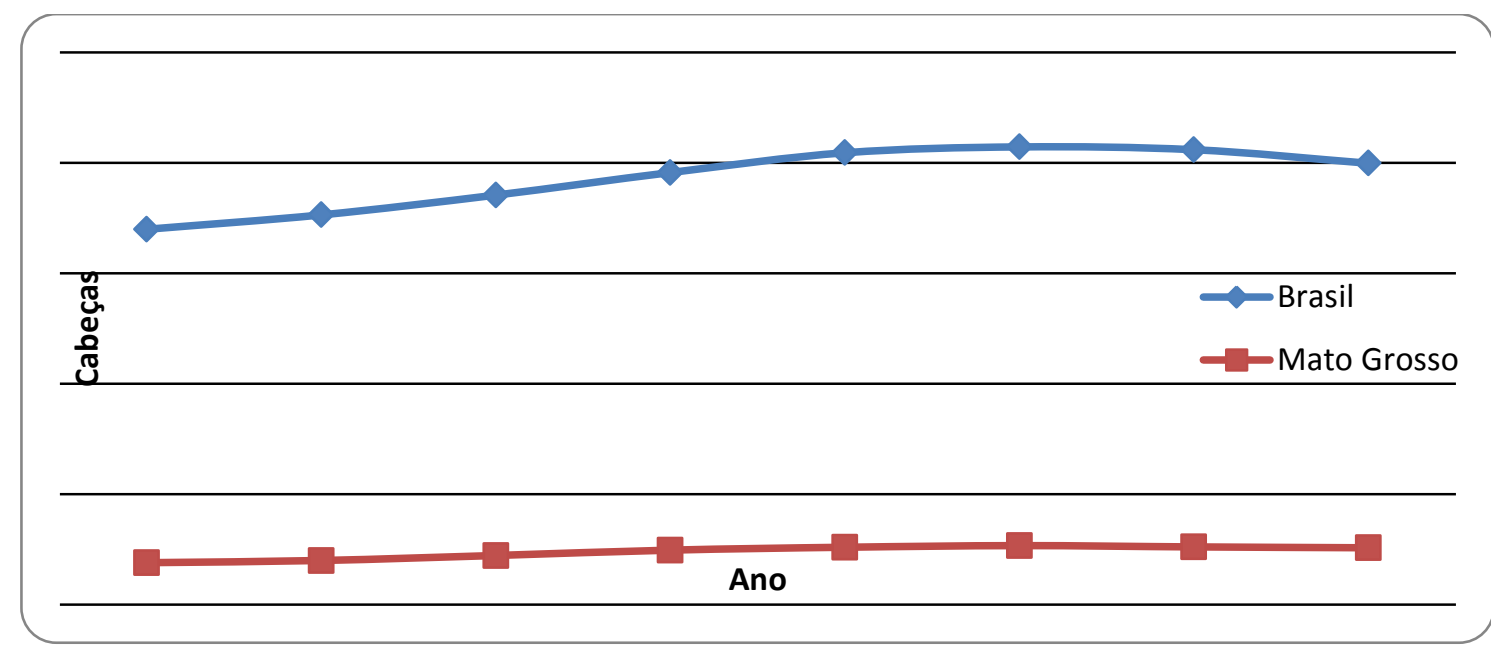

Fonte: IBGE (2009).

Figura 4. Evolução do rebanho bovino no Brasil e em MT entre 2000 e 2007.

Os motivos para a desaceleração do crescimento do rebanho bovino de Mato Grosso foram a desvalorização do dólar a partir do ano de 2004, que desestimulou a exportação de carne bovina, o que provocou a diminuição de investimentos na pecuária, e também a queda no preço da arroba do gado nos últimos anos (Souza, 2006).

O mesmo ocorreu com o abate no estado, conforme a figura 5: 


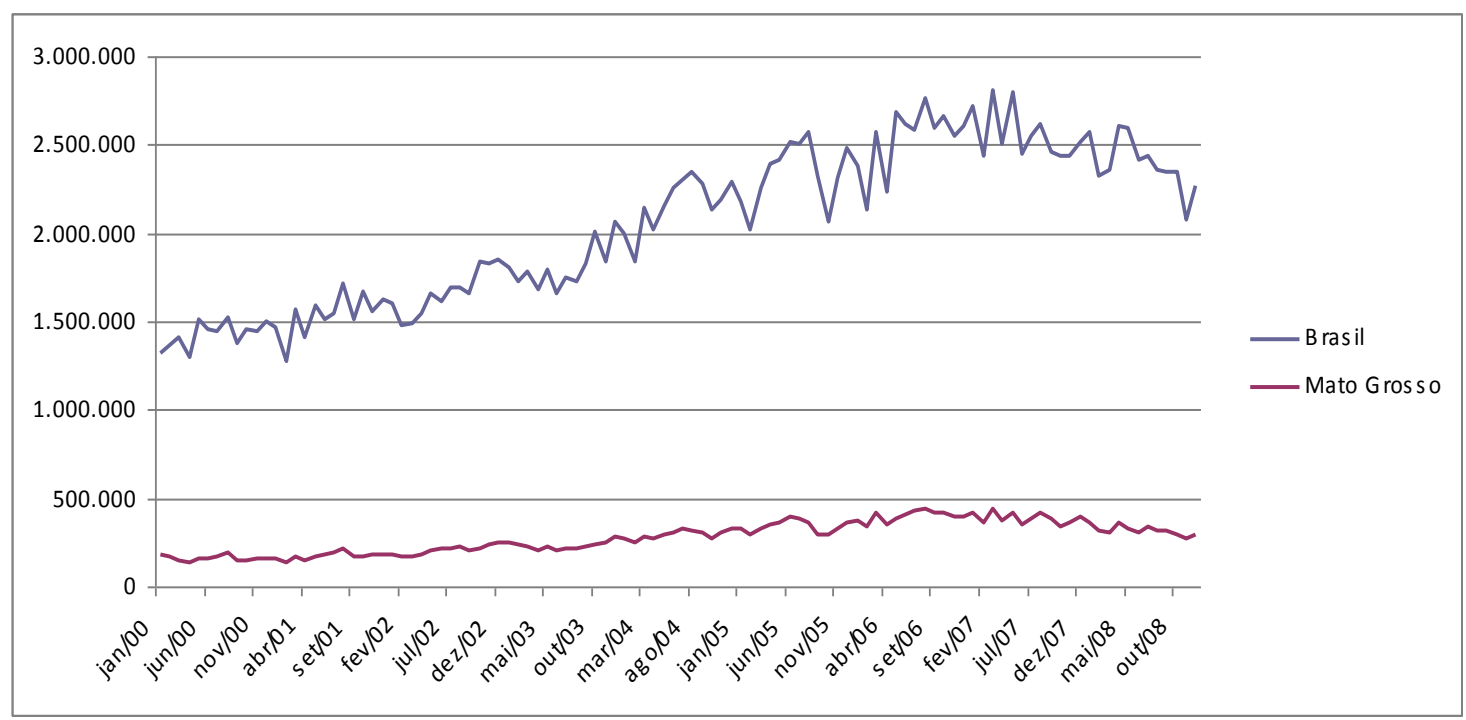

Fonte: IBGE (2009).

Figura 5. Evolução do abate de bovino no Brasil e em MT entre 2000 e 2007.

A pecuária no Brasil tem como base alimentar para os rebanhos as pastagens, cerca de 220 milhões de hectares de pastagens, que ocupam $26 \%$ de todo o território nacional (ESTERMANN, 2006). O rebanho mato-grossense, o maior rebanho brasileiro, ocupa 21,7 milhões de hectares com áreas de pastagens, o que representa $24 \%$ da área do Estado, enquanto a agricultura ocupa apenas 9,5\% da área total do Mato Grosso (ESTERMANN, 2006).

\subsection{Pastagem}

Um dos fatores que fazem diferença na atividade de bovinocultura é o tipo de pastagem oferecida ao rebanho. O tipo de pastagem deve ser escolhido de acordo com o tipo de solo, clima da região e disponibilidade hídrica.

Há dois tipos de pastagens forrageiras usadas no Brasil, a pastagem nativa ou natural e artificial ou cultivada (MARION, 2006, P. 75). A pastagem nativa ou natural é a vegetação nativa que nasce naturalmente nos campos, sem a necessidade da intervenção do homem, e que tenha valor forrageiro, que sirva de alimentação para o gado. O tipo de vegetação nativa varia de acordo com cada região no Brasil. Na região Sul se destacam os campos, no Nordeste a caatinga e no Centro-Oeste o cerrado.

A pastagem artificial é semeada, depende do cultivo do homem. Nas regiões tropicais, as pastagens forrageiras artificiais são utilizadas na criação de gado pelos fatores nutricionais. 
As espécies forrageiras representam as plantas de interesse econômico mais cultivadas no mundo (RODRIGUES, 1986, apud MELLO et al).

Em regiões onde as chuvas são regulares, a produção de forrageiras para o sustento do gado é mais fácil. Nas regiões mais secas, as pastagens das espécies braquiárias são capazes de manter a produção e formar canais e galerias para que as plantas menos agressivas consigam desenvolver suas raízes em busca de água e nutrientes nas camadas mais profundas do solo. (MIELNICZUK, 1996, apud MELLO et al).

Entre as espécies de Brachiaria, a espécie brizantha se destaca pela qualidade. O brizantha tem um bom desempenho devido à sua adaptação a todos os tipos de solo, porém a espécie apresenta crescimento prostrado e agressivo, o que não permite a associação com leguminosas, isso dificulta a diversificação e a complementação alimentar dos animais no campo (GOEDERT et al., 1985, apud MELLO et al).

\subsection{Pastoreio}

Pastoreio ou pastejo é o processo pelo qual os animais consomem plantas para adquirir energia e nutrientes, é o processo de alimentação do gado. Manejo de pastejo envolve o controle deste processo pelo homem, especialmente pela manipulação dos animais com o objetivo de otimizar a produção.

Marion (2007, p. 23) descreve sobre dois tipos de pastoreio: o pastoreio rotativo ou rodízio e pastoreio contínuo. O pastoreio rotativo é caracterizado pelo período de repouso para o pasto. As propriedades são divididas em áreas menores, os piquetes, que permite ao pecuarista trocar os animais de pasto a cada período de 30 dias aproximadamente.

A técnica do rodízio é um processo moderno, que oferece a vantagem ao pecuarista de não mais precisar fazer reformas na forragem. Pois, com a adoção deste método, há espaço de tempo para que a forragem se recupere, garantindo pasto suficiente para alimentar os bovinos mesmo na época de seca (MARION, 2007).

O pastoreio contínuo não há rodízio de piquete, os animais permanecem durante todo o ano no mesmo pasto. Mas assim como no pastoreio rotativo é determinado o número de cabeças de gado por hectare, separados por categorias. As categorias podem ser por idade ou por tipo de atividade, cria, recria e engorda. É importante fazer esse tipo de controle para que não exceda o número de animais e diminua a produtividade ou haja pasto ocioso (MARION, 2007). 


\subsection{Suplementação Alimentar}

A qualidade e a produtividade de gado de corte dependem da qualidade da pastagem forrageira, do valor nutricional que essas gramíneas oferecem ao animal, dependem também da genética do animal e como ele irá se adaptar ao tipo de pastagem.

Para que o gado tenha um bom crescimento e ganho de peso em um curto espaço de tempo, as exigências nutricionais do animal estão além do pastoreio. Pois a qualidade da forragem é alterada à medida que a planta amadurece, e coincide com o início da estação da seca. Com uma forragem de baixa qualidade "o animal não consegue alcançar sua demanda em nutrientes para manter uma curva crescente de crescimento", pode estender a idade de abate ou de primeira cria (THIAGO, 1999).

\footnotetext{
A demanda do animal por nutrientes, nas épocas de seca na região Centro Oeste só é possível por meio do uso da suplementação alimentar. O objetivo da suplementação é diminuir a deficiência causada pela falta de pastagens. A estação do ano mais adequada para o seu uso seria a da seca, entre os meses de junho a setembro, quando as pastagens estão maduras, com baixo crescimento e baixos teores de nutrientes (THIAGO, 1999).
}

O suplemento alimentar tem função protéica, conhecido como sal protéico. É uma alternativa de baixo custo para suplementação alimentar do gado na época da seca. Há também outro tipo de suplemento alimentar, conhecido como mistura múltipla (THIAGO, 1999).

O sal protéico contém mistura mineral na sua composição e também um farelo protéico, que adiciona fontes extras de nutrientes (proteína e energia), o objetivo fundamental do uso do sal protéico é suprir a deficiência de nitrogênio das bactérias ruminais. Isto ocorrendo, vai haver um aumento no consumo da pastagem e, como conseqüência, maior ingestão de nutrientes, revertendo uma situação de perda de peso (COELHO, 2002).

A mistura múltipla pode ser usada em casos específicos, como em bezerros após a desmama, animais destinados a recria e engorda e na época de chuva (COELHO e FILHO, 2002).

\section{METODOLOGIA}


Comparativo de custos e resultados em sistemas de produção de bovinos: o caso da fazenda Santa Luzia Ângela Golas

Antonielle Pagnussat

Laércio Juarez Melz

A pesquisa foi realizada por meio de um levantamento de custos da atividade de criarecria e engorda e da caracterização da atividade na região em relação ao Brasil. Esta pesquisa é importante para verificar se a atividade de engorda que é tida como a mais vantajosa, por proporcionar melhores resultados dentre as demais atividades no ramo da bovinocultura, realmente é mais lucrativa para o produtor.

Com o objetivo de estudar o custo de criação de bovinos, aplicando sistemas de custeio, utilizou-se como objeto de estudo uma propriedade do estado do Mato Grosso, localizada no município de Juína, denominada neste estudo como propriedade Santa Luzia.

As atividades desenvolvidas pela propriedade Santa Luzia são cria, recria e engorda de bovinos. A propriedade é destinada exclusivamente para as atividades de criação de gado, sendo esta a única fonte da receita da mesma. A princípio, eram realizadas as atividades de cria e recria, comercializando bezerros e novilhos magros, no entanto, decidiu-se por ampliar as atividades, foi adquirido o primeiro lote de novilhos magros para engorda.

Quanto ao objetivo a pesquisa realizada é qualitativa, contendo estudo de caso. Quanto aos procedimentos, a pesquisa foi realizada embasada em dados bibliográficos, coletados de livros, artigos, teses e conteúdo da internet.

O estudo de caso, o levantamento e a coleta de dados deram-se na propriedade Santa Luzia, localizada no município de Juína, Mato Grosso, propriedade esta destinada à atividade de bovinocultura, com dados do período de janeiro a dezembro de 2008.

A pesquisa se iniciou com a escolha e apresentação da revisão teórica, introduzindo o conhecimento básico de Contabilidade de Custo, métodos de custeio e a bovinocultura no Brasil e no Mato Grosso.

O primeiro passo é o levantamento dos custos totais da propriedade do ano de 2008, os custos foram divididos e classificados em custos diretos e indiretos, com o auxílio da seguinte tabela:

Tabela 1 - Classificação dos custos

Custos diretos

Aluguel

Vacinas

Vermífugos

Vitaminas e remédios

Custos indiretos

Combustíveis e Lubrificantes

Deprec. Matrizes e Reprodutores

Exaustão das pastagens e da terra

Volume 3, Número 5

Revista UNEMAT de Contabilidade

Jan./Jun. 2014

UNEMAT 
Manutenção da propriedade

Mão-de-obra de terceiros

Outros custos

Suplementos minerais e protéicos

Os custos diretos (aluguel, vacinas, vermífugos, vitaminas e remédios) não necessitam de rateio para alocação ao produto, porque são alocados diretamente a cada cabeça de gado, já os custos indiretos precisaram ser rateados para constituírem o custo total de cada cabeça, utilizando o método de custeio por absorção.

Quanto à classificação dos custos em fixos e variáveis, apenas a depreciação de matrizes e reprodutores e a exaustão das pastagens e da terra são custos fixos, os demais custos variam de acordo com a quantidade de cabeças do rebanho.

A amostra deste estudo é um lote com 334 cabeças, incluindo matrizes, reprodutores, bezerros e novilhos magros, incluindo machos e fêmeas e novilhos para engorda, distribuídos da seguinte forma:

Tabela 2 - Plantel Propriedade Santa Luzia

\begin{tabular}{lr}
\hline Matrizes & 100 cabeças \\
Reprodutores & 05 cabeças \\
Bezerros (as) de 0 a 12 meses & 87 cabeças \\
Novilhos (as) magros de 13 a 24 meses & 68 cabeças \\
Novilhos de 25 a 36 meses & 74 cabeças \\
\hline
\end{tabular}

O tamanho da população analisada foi de 850 animais. A amostra selecionada ofereceu margem de erro de 4,9\% com nível de confiança de $95 \%$.

\section{ANÁLISE DOS RESULTADOS}

O estudo de caso foi realizado na propriedade Santa Luzia, localizada na MT-319, no município de Juína - MT. O tamanho da propriedade é de 109 hectares, incluindo a área de mata destinada à reserva de legal.

A propriedade é utilizada apenas para atividade de cria e recria. A atividade de engorda é realizada em propriedade locada. Com o período de forte seca da região nordeste do Estado, que ocorre durante o inverno, é necessária a locação de pastagens para os demais bovinos. 
Comparativo de custos e resultados em sistemas de produção de bovinos: o caso da fazenda Santa Luzia Ângela Golas

Antonielle Pagnussat

Laércio Juarez Melz

O sistema de criação do gado é extensivo, muito comum na região, utilizando-se da técnica de pastoreio rotativo, no qual o gado está sempre em rodízio para o pasto ser recuperado. O gado é da raça Nelore e o pasto é da espécie Brizantã.

O levantamento dos custos compreende o ano de 2008. Os gastos identificados que formam o custo de cada cabeça de gado são: depreciação de matrizes e reprodutores, depreciação da terra e manutenção de pastagens, aluguel, suplementos minerais e protéicos, adubos e fertilizantes, vacinas, vermífugos e remédios, lubrificantes e combustíveis. Há ainda os custos esporádicos de manutenção da propriedade, como manutenção de cercas, de currais e a compra de pequenos equipamentos agrícolas.

Os custos indiretos foram classificados em fixos e variáveis. Os custos fixos compreendem apenas a depreciação das matrizes e reprodutores e a exaustão das pastagens e da terra, os demais são custos variáveis, variam de acordo com a quantidade de cabeças de gado, até mesmo o aluguel é um custo variável, pois é contratado por cabeça.

A propriedade ainda não tem energia elétrica instalada, assim como não possui instalações de moradia. A propriedade também não dispõe de funcionários fixos, a mão-deobra utilizada no decorrer do ano para manutenção da mesma é apenas dos proprietários. São contratados funcionários apenas na época de vacinação do gado, quando há necessidade de manejo do gado entre pastos e outros serviços temporários.

Os dados foram levantados com base em informações do proprietário e em documentos fiscais. A partir deste levantamento de custos, obteve-se os seguintes resultados, conforme o quadro 2:

\begin{tabular}{|c|c|c|}
\hline \multirow{9}{*}{ 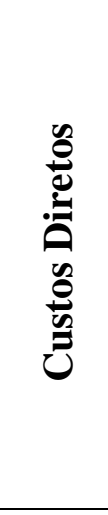 } & Custo de Bezerros & 87 cabeças \\
\hline & Suplementos minerais e protéicos & $\mathrm{R} \$ 3.682,06$ \\
\hline & Vacinas & $\mathrm{R} \$ 472,61$ \\
\hline & Vermífugos & $\mathrm{R} \$ 454,65$ \\
\hline & Vitaminas e outros remédios & $\mathrm{R} \$ 331,16$ \\
\hline & Deprec. Matrizes e Reprodutores & $\mathrm{R} \$ 6.033,87$ \\
\hline & Exaustão das pastagens e da terra & $\mathrm{R} \$ 9.177,10$ \\
\hline & Aluguel & $\mathrm{R} \$ 2.323,74$ \\
\hline & Mão-de-obra de terceiros & $\mathrm{R} \$ 954,19$ \\
\hline \multirow{4}{*}{ 苍 } & Combustíveis e Lubrificantes & $\mathrm{R} \$ 637,06$ \\
\hline & Outras despesas & $\mathrm{R} \$ 561,29$ \\
\hline & Manutenção da propriedade & $\mathrm{R} \$ 252,58$ \\
\hline & Total dos custos & $\mathrm{R} \$ 24.880,31$ \\
\hline \multicolumn{3}{|c|}{ Quadro 2 - Custos dos Bezerros } \\
\hline \multicolumn{2}{|c|}{ Volume 3, Número 5} & de Contabilidade \\
\hline \multicolumn{2}{|c|}{ Jan./Jun. 2014} & UNEMAT \\
\hline
\end{tabular}


Comparativo de custos e resultados em sistemas de produção de bovinos: o caso da fazenda Santa Luzia Ângela Golas

\begin{tabular}{|c|c|c|}
\hline \multirow{10}{*}{ 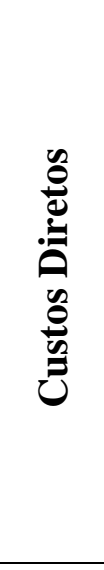 } & Custo de Novilhos & 68 cabeças \\
\hline & Valor dos bezerros & $\mathrm{R} \$ 19.446,68$ \\
\hline & Suplementos minerais e protéicos & $\mathrm{R} \$ 2.877,94$ \\
\hline & Vacinas & $\mathrm{R} \$ 369,39$ \\
\hline & Vermífugos & $\mathrm{R} \$ 355,35$ \\
\hline & Vitaminas e outros remédios & $\mathrm{R} \$ 258,84$ \\
\hline & Deprec. Matrizes e Reprodutores & $\mathrm{R} \$ 4.716,13$ \\
\hline & Exaustão das pastagens e da terra & $\mathrm{R} \$ 7.172,90$ \\
\hline & Mão-de-obra de terceiros & $\mathrm{R} \$ 745,81$ \\
\hline & Aluguel & $\mathrm{R} \$ 1.816,26$ \\
\hline \multirow{4}{*}{ 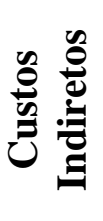 } & Combustíveis e Lubrificantes & $\mathrm{R} \$ 497,94$ \\
\hline & Outras despesas & $\mathrm{R} \$ 438,71$ \\
\hline & Manutenção da propriedade & $\mathrm{R} \$ 197,42$ \\
\hline & Total dos Custos & R\$ 38.893,37 \\
\hline
\end{tabular}

Quadro 3 - Custos de Novilhos

Os bezerros e novilhos nasceram na propriedade, absorvendo assim o valor dos custos da propriedade relativos à atividade de bovinocultura, através do sistema de custeio por absorção, os custos foram rateados de forma proporcional entre bezerros e novilhos (quadro $3)$.

O custo de vacinas, um custo direto, foi alocado de acordo com o lote que recebeu as vacinas. Durante o ano houve três campanhas de vacinação contra febre aftosa. A primeira em fevereiro, para animais de 0 a 12 meses, a segunda em maio, para animais de 0 a 24 meses, e em novembro para todos os animais.

Os custos mais elevados foram depreciações de matrizes e reprodutores, exaustão das pastagens e da terra e com suplementos minerais e protéicos. A partir do rateio dos custos, obteve-se o valor de cada animal, cada cabeça de bezerro custa $\quad \mathrm{R} \$ 285,98$ e de novilho $\mathrm{R} \$ 571,96$.

Os animais para engorda, garrotes na média de 18 meses, foram adquiridos no final do ano de 2007, no valor de $\mathrm{R} \$ 520,00$, por isso não acumulam custos de depreciação de matrizes e reprodutores, e exaustão de pastagens. Mas como a atividade de engorda é realizada em pastagens locadas, o custo com aluguel das pastagens é bem mais elevado, se comparado ao aluguel temporário utilizado na época da seca.

\begin{tabular}{lcr|r|}
\hline$U=0$ & Custo de bovinos para engorda & $\mathbf{7 4}$ cabeças \\
\hline
\end{tabular}


Comparativo de custos e resultados em sistemas de produção de bovinos: o caso da fazenda Santa Luzia Ângela Golas

Antonielle Pagnussat

Laércio Juarez Melz

\begin{tabular}{|c|c|c|}
\hline & Valor de aquisição de gado & $\mathrm{R} \$ 38.480,00$ \\
\hline & Suplementos minerais e protéicos & $\mathrm{R} \$ 4.190,00$ \\
\hline & Vacinas & $\mathrm{R} \$ 192,00$ \\
\hline & Aluguel & $\mathrm{R} \$ 7.104,00$ \\
\hline & Mão-de-obra de terceiros & $\mathrm{R} \$ 720,00$ \\
\hline \multirow{3}{*}{ 旁 } & Combustíveis & $\mathrm{R} \$ 520,00$ \\
\hline & Outras despesas & $\mathrm{R} \$ 500,00$ \\
\hline & Total dos custos & $\mathrm{R} \$ 51.706,00$ \\
\hline
\end{tabular}

Quadro 4 - Custo de bovinos para engorda

O aluguel representa a maior parcela do custo, seguido dos suplementos minerais e protéicos. O custo de criação de cada cabeça ficou em $\mathrm{R} \$ 698,73$.

Se estes animais fossem vendidos no final do ano de 2008, ou logo no início de 2009. Adotando o preço de mercado local, os bezerros (as) e novilhos (as) são comercializados por cabeça, já o boi gordo é comercializado por arroba. O seguinte resultado seria encontrado:

Tabela 3 - Custo x Preço de Mercado

\begin{tabular}{lccc}
\hline & Custo & $\begin{array}{c}\text { Preço } \\
\text { Mercado }\end{array}$ & $\begin{array}{c}\text { Lucro } \\
\text { p/cabeça }\end{array}$ \\
\hline Bezerro 0 a 12 meses & 285,98 & 520,00 & 234,02 \\
Bezerra 0 a 12 meses & 285,98 & 350,00 & 64,02 \\
Novilho 13 a 24 meses & 571,96 & 750,00 & 178,04 \\
Novilha 13 a 24 meses & 571,96 & 550,00 & $(21,96)$ \\
Boi gordo & 698,73 & $1.050,00$ & 351,27 \\
\hline
\end{tabular}

Este é o primeiro lote de gado para engorda e ainda não foi comercializado, para este cálculo foi utilizado o valor atual da arroba, que é de $\mathrm{R} \$ 70,00$, o gado está com uma média de 15 arrobas cada cabeça, para abate é necessário que o gado tenha pelo menos 17 arrobas.

Até o momento da venda, o custo do lote para engorda ainda irá aumentar o custo, por isso foi calculado com 15 arrobas, peso atual. Quanto ao lucro de cada tipo de atividade, o gado para engorda é o que oferece maior margem de lucro, mesmo em pasto locado, seguidos dos bezerros e novilhos, quanto às fêmeas o lucro é muito baixo, quando não ocorre prejuízo, como no caso das novilhas.

\section{CONSIDERAÇÕES FINAIS}


O objetivo desta pesquisa foi fazer o levantamento dos custos da atividade de bovinocultura no sistema de cria-recria e engorda na propriedade Santa Luzia. Até então, desenvolvia as atividades de cria e recria, e adquiriu o primeiro lote de gado para engorda.

Através do levantamento de custos e do levantamento do preço praticado na região, concluiu-se que para este proprietário é mais vantajosa a atividade de engorda. Mesmo sendo praticada em pasto locado, há maior retorno financeiro para o proprietário do que nas demais.

A limitação da pesquisa ocorre porque o lote de gado para engorda não foi vendido no período abordado no levantamento de dados, o que não permitiu o conhecimento do valor real da venda, porém foi adotado o valor de mercado do boi gordo do final de 2008.

Para a atividade de engorda faz-se necessário maior investimento inicial, na compra de lotes de novilhos magros, e no momento da comercialização o gado precisa ter atingido o peso mínimo para abate aceito pelos frigoríficos, que é de 17 arrobas. Por isso, muitos pecuaristas se dedicam à atividade de cria e recria, na qual, quando preciso, há algumas de cabeças de gado que podem ser comercializadas no mercado.

\section{REFERÊNCIAS}

ANDERSON, David R.; SWEENEY, Dennis J.; WILLIAMS, Thomas A. Estatística Aplicada à Administração e Economia. Tradução da 2. ed. norte-americana Luiz Sérgio de Castro Paiva. São Paulo: Pioneira Thomson Learning, 2002. Tradução de: Essentials of Statistics for Business and Economics.

AGUIAR, Ludmilla Moura de Souza. BARIONI, Luís Gustavo. A diversificação dos sistemas de produção de bovinos de corte no Brasil: produção econômica e conservação ambiental. Disponível em: http://www.agrosoft.org.br/agropag/27353.htm.2007. Acesso em 20.11.2008.

BATALHA, Mario Otavio. Gestão Agroindustrial. $3^{\text {o }}$ ed. São Paulo: Atlas, 2007.

CARDOSO, Esther Guimarães. Confinamento de bovinos. Disponível em: http://www.cnpgc.embrapa.br/publicacoes/naoseriadas/cursosuplementacao/confinamento. Acesso em 28.10.2008.

IBGE, MT. Censo Agropecuário 2006. Disponível em: http://www.ibge.gov.br/ home/estatistica/economia/agropecuaria/censoagro/2006. Acesso em 15.08.2008

IBGE, Instituto Brasileiro de Geografia e Estatística. Sistema IBGE de Recuperação Automática - SIDRA. Disponível em: <http://www.sidra.ibge.gov.br /bda/tabela/protabl.asp?z=t\&o=22\&i=P>. Acesso em: 10.032009. 
CREPALDI, Silvio Aparecido. Contabilidade Gerencial: teoria e prática. $3^{\circ}$ ed. São Paulo: Atlas, 2006.

COELHO, Kenneth M. Sal protéico. Disponível em: http://www.salfazendeiro.com.br/exibe.php?id=7\&cod_editorial=3\&url_back=cartilha.php\&p ag=0\&busca. Acesso em 25.10.2008.

COELHO, Kenneth M. FILHO, Michel Calarge. Sal Protéico e Mistura Múltipla. Sal fazendeiro. 14/08/2002. Disponível em: http://www.mnp.org.br/index.php?pag=ver_noticia\&id=347141. Acesso 25.08.2008.

VANDERBECK, Edward J. NAGY, Charles F; Tradução Robert Brian Taylor. Contabilidade de Custos. $11^{\circ}$ ed. São Paulo: Pioneira Thomson Learning, 2003.

ESTERMANN, Alexander. O pecuarista que produz capim. 28/07/2006. Disponível em: http://www.aprmt.com.br/artigos/artigo.asp?cod=216. Acesso em 19.09.2008.

GREIF, Sérgio. Vegetarianismo e Conservação Ambiental. Disponível em: http://www.svb.org.br/depmeioambiente/VegetarianismoeConservacaoAmbiental.htm.

Acesso em 25.09.2008.

Secretaria da Receita Federal. INSTRUÇÃO NORMATIVA Nº 17, DE 04 DE ABRIL DE 1996. http://www.receita.fazenda.gov.br/legislacao/ins/_ant2001/ant1997/ 1996/insrf01796.htm. Acesso em: 25.09.2008.

IUDÍCIBUS, Sérgio de. Contabilidade Gerencial. 6º ed. São Paulo: Atlas, 1998.

LEONE, George Sebastião Guerra. LEONE, Rodrigo José Guerra. Dicionário de Custos. São Paulo: Atlas, 2004.

MARION, José Carlos. Contabilidade Básica. 7º ed. São Paulo: Atlas, 2004.

MARION, José Carlos. Contabilidade Rural: Contabilidade Agrícola, Contabilidade da Pecuária, Imposto de Renda Pessoa Jurídica. 8 ed. São Paulo: Atlas, 2006.

MARION, José Carlos. SEGATTI, Sonia Maria. Contabilidade da Pecuária. $8^{\circ}$ ed. São Paulo: Atlas, 2007.

MARION, José Carlos. Contabilidade e Controladoria em Agrobusiness. São Paulo: Atlas, 1996.

MARTINS, Eliseu. Contabilidade de Custos. $9^{\circ}$ ed. São Paulo: Atlas, 2003.

MEGLIORINI, Evandir. Custos. São Paulo: Makron Books, 2001.

MEISTER, Luiz Carlos. (Coord.) Diagnóstico da cadeia produtiva agroindustrial da bovinocultura de corte do estado de mato grosso. Cuiabá, 2007. 
Comparativo de custos e resultados em sistemas de produção de bovinos: o caso da fazenda Santa Luzia Ângela Golas

Antonielle Pagnussat

Laércio Juarez Melz

MELLO, Dimas de. (Coord.) et al. Produção de massa seca de Brachiaria brizantha e Andropogon gayanus, sob diferentes processos de preparo do solo. 2003. Disponível em: http://www.ufmt.br/agtrop/revista7/doc/07.htm. Acesso em 19.09.08

O’SUlLIVAN, Arthur. SHEFFRIN, Steven M. Princípios de Economia. 1998.

PADOVEZE, Clóvis Luís. Contabilidade Gerencial: um enfoque em sistema de informação contábil. $4^{\circ}$ ed. São Paulo: Atlas, 2004.

QUADROS, Danilo Gusmão de. Confinamento de bovinos de corte. Disponível em: http://www.neppa.uneb.br/textos/publicacoes/cursos/confinamento_bovinos_corte.pdf.

Acesso em 20.01.2009

SÁ, Antonio Lopes de. Teoria da Contabilidade. $4^{\circ}$ ed. São Paulo: Atlas, 2006.

SOUZA, Oswaldo Braga de. Desmatamento na Amazônia e agronegócio. http://www.socioambiental.org/nsa/index_html, 2006. Acesso em 03.04.09

THIAGO, Luiz Roberto Lopes. Suplementação de bovinos em pastejo. Disponível em: http://www.cnpgc.embrapa.br/publicacoes/naoseriadas/suplementhiago/, 1999. Acesso em 19.09.08

VASCONCELLOS, Marco Antonio Sandoval. GARCIA, Manuel Enriquez. Fundamentos de Economia. $2^{\circ}$ ed. São Paulo: Saraiva, 2004. 